\title{
Impregnated Nanofibrous Mat with Nanogel of Citrus sinensis Essential Oil as a New Type of Dressing in Cutaneous Leishmaniasis
}

\author{
Ali Ghanbariasad 1(i), Fatemeh Amoozegar ${ }^{2}$, Mahya Rahmani ${ }^{\text {(i) }}$, Elham Zarenezhad ${ }^{4}$ (i), Mahmoud \\ Osanloo 5 , * (i)
}

1 Department of Medical Biotechnology, School of Medicine, Fasa University of Medical Sciences, Fasa, Iran; a.ghanbari@fums.ac.ir (AG);

2 Student Research Committee, Fasa University of Medical Sciences, Fasa, Iran; amoozegar.fateme@gmail.com (F.A.);

3 Department of Medical Nanotechnology, School of Advanced Technologies in Medicine, Tehran University of Medical Sciences, Tehran, Iran; mahya.rahmani@gmail.com (M.R.);

4 Noncommunicable Diseases Research Center, Fasa University of Medical Sciences, Fasa, Iran; el.zarenezhad@gmail.com (E.Z.);

5 Department of Medical Nanotechnology, School of Advanced Technologies in Medicine, Fasa, Iran; m.osanloo@fums.ac.ir (M.O.);

* Correspondence: m.osanloo@fums.ac.ir,osanloo_mahmood@yahoo.com;

Received: 14.11.2020; Revised: 4.12.2020; Accepted: 6.12.2020; Published: 8.12.2020

\begin{abstract}
Leishmaniases are a group of diseases caused by the Leishmania genus. Essential oils (EO)s have recently received more attention for the development of new green drugs. In this study, Citrus sinensis $\mathrm{EO}$ was used as an antileishmanial agent; its half-maximal inhibitory concentration $\left(\mathrm{IC}_{50}\right)$ against promastigotes of Leishmania tropica and Leishmania major was observed at 151.13 and 108.31 $\mu \mathrm{g} / \mathrm{mL}$. After that, the nanoemulsion-based nanogel of $C$. sinensis was prepared to improve its stability, potency, and facilitated topical usage. By adding carbomer $940(2 \% \mathrm{w} / \mathrm{v})$ to the prepared nanoemulsion with a $225 \pm 7 \mathrm{~nm}$ droplet size, the nanogel was prepared. The nanogel was then impregnated on the electrospun nanofibers of chitosan-polycaprolactone, diameter $=\sim 200 \mathrm{~nm}$. The prototype's leishmanicidal effect was substantially better than the non-formulated EO; both species' viabilities were reduced to $\sim 0 \%$. The prepared sample could be used as a new type of dressing for cutaneous leishmaniasis; moreover, it could be considered an excellent candidate for in-vivo studies.
\end{abstract}

Keywords: Citrus sinensis: Leishmania tropica; Leishmania major; chitosan-polycaprolactone nanofibers; nanogel.

(C) 2020 by the authors. This article is an open-access article distributed under the terms and conditions of the Creative Commons Attribution (CC BY) license (https://creativecommons.org/licenses/by/4.0/).

\section{Introduction}

Obligate intra-macrophage protozoa of the Leishmanias genus are responsible for leishmaniases, a group of vector-borne diseases [1]. The three main forms of leishmaniasis are cutaneous leishmaniasis, visceral leishmaniasis, and mucocutaneous leishmaniasis; they are induced by around 20 different species Leishmania [2]. Around 100 countries in tropical and subtropical regions are involved with cutaneous leishmaniasis, the most common form of leishmaniasis [3, 4]. Leishmania major and Leishmania tropica in the old world, including Iran, Afghanistan, Saudi Arabia, and Syria, are responsible for cutaneous leishmaniasis in rural and urban areas, respectively $[5,6]$. 
Essential oils (EOs) are naturally oily liquids secreted as secondary metabolites in the aromatic plants. They are extracted using different approaches such as hydro-distillation, steam distillation, and dry-distillation from different parts of plants, including stem, bark, and fruit $[7,8]$. EOs possess many biological activities, such as the leishmanicidal effect. For instance, the potency of Citrus sinensis essential oil (CSEO) against L. panamensis and L. braziliensis has been reported previously [9]. Recently, the volatility of EOs could be controlled by formulating them into different nanoformulations, including nanoemulsions, polymeric nanoparticles, nanogels, and niosomes [10, 11]. Nanogels are good candidates for topical/transdermal applications; they possess many unique behaviors like fluidic nature, acquiring any shape during penetration, and modulating skin barrier for better penetration [12, 13].

Electrospinning is a versatile and straightforward technique for preparing nanofibers (NFs) $[14,15]$. Electrospun NFs have been widely used in medical and health applications; for example, the use of NFs of chitosan (Chi) and polycaprolactone (PCL) in tissue engineering, wound dressing, and filtration [16, 17]. Moreover, the encapsulation of active ingredients into electrospun NFs is common. However, some practical challenges have remained still; electrospinnability and co-dissolving cargo and polymers, especially when the cargo is volatile (e.g., EO) [18, 19]. Furthermore, for observing the effect of a drug, the concentration must be reached to a certain range, while EO/drugs' weight could be loaded in the NFs are low. Thus, after-treatment methods may provide a useful solution for these issues.

In this study, the leishmanicidal activity of CSEO against promastigotes of L. major and L. tropica were first investigated. After that, for stability and potency improvement, a nanoemulsion-based nanogel of CSEO was prepared. To easy use in a topical manner, the nanogel was then impregnated on the Chi-PCL electrospun NFs. Finally, the leishmanicidal effect of those was compared.

\section{Materials and Methods}

\subsection{Materials.}

CSEO was purchased from Green Plants of Life Co. (Iran). Tween 80, PCL (80000 $\mathrm{Mw}$ ), low molecular Chi (75-85\% DD), Sodium hydroxide ( $\mathrm{NaOH})$, Phosphate Buffered Saline (PBS) were bought from Merck Chemicals (Germany). Pasteur Institute of Iran supplied $L$. major (MHOM/IR/75/ER) and L. tropica (MHOM/SU/74/K27). Hexafluoro-2-propanol (HFIP), as the solvent of polymers in electrospinning, was purchased by SUVCHEM Co. (India). Carbopol 940 was obtained from SDFCL Co. (India).

\subsection{GC-MS analysis.}

Ingredients of CSEO were identified using GC-MS analysis, as described in our previous report [20].

\subsection{Preparation and characterization of Chi-PCL NFs.}

\subsubsection{Preparation.}

Powder of Chi (1\% w/v) and granules of PCL (14\% w/v) was dissolved in HFIP, and were mixed $0.75-3.5 \% \mathrm{w} / \mathrm{v}$ ( $24 \mathrm{~h}$, room temperature). The Chi-PCL solution was then loaded in a $10 \mathrm{~mL}$ syringe (internal diameter $12 \mathrm{~mm}$ ) connected to a blunted metal needle in an 
electrospinning machine (Fanavaran Nano-Meghyas Co. Iran). Also, a power cable $(15 \mathrm{kV})$ was attached to the needle. The polymer solution was injected $(0.8 \mathrm{~mL} / \mathrm{h})$ using a syringe pump, and the distance between the needle and the rotating collector (100 rpm) was fixed at $100 \mathrm{~mm}$. The collector's surface was wrapped with aluminum foil to facilitate the separation of the prepared NFs [21]. Morphology, size, and characterization of the obtained fibers were investigated using scanning electron microscopy (SEM), water contact angle measurement, and Attenuated Total Reflection Fourier Transform Infrared (ATR-FTIR).

\subsubsection{Scanning electron microscopy.}

SEM was used to investigate the morphology, size, and size distribution of the NFs (TESCAN-Vega 3, Czech Republic). The samples were coated with gold vapors. An image processing software (Free version of Digimizer, MedCalc Software Ltd, Belgium) was used to analyze the diameter of NFs.

\subsubsection{Water contact angle measurement.}

The wettability of the NFs was investigated using a contact angle measurement instrument (Sharif Solar Co. Iran). Seven $\mu \mathrm{L}$ of de-ionized water was injected on the NFs mat $(1 \mathrm{~cm} \times 1 \mathrm{~cm})$, and its contact angle was recorded at $5 \mathrm{~s}$ [22].

\subsubsection{ATR-FTIR.}

The preparation of Chi-PCL NFs was confirmed by identifying the functional groups of the used polymer and final NFs. The study was performed using ATR-FTIR analysis in the wavelength range of $3500-500 \mathrm{~cm}^{-1}$ (Bruker Company, Model Tensor II, USA).

\subsection{Preparation and characterization of nanoemulsion-based nanogel.}

\subsubsection{Nanoemulsion.}

Oil in water nanoemulsion of CSEO was prepared using the spontaneous method. The CSEO $(35 \mu \mathrm{L})$ and tween $80(125)$ were mixed at $2000 \mathrm{rpm}$ for 10 minutes. Distilled water was then added drop-wise up to the desired volume $(5000 \mu \mathrm{L})$ and stirred for $35 \mathrm{~min}$. Droplet size and droplet size distribution (SPAN) of the nanoemulsion were evaluated using a DLS type apparatus (dynamic light scattering, scatteroscope, K-ONE NANO. LTD, Korea). SPAN was calculated by $\mathrm{d} 90-\mathrm{d} 10$ / d50, where $\mathrm{d}$ is the diameter of the droplets and $\mathrm{x}$ (i.e., 10, 50, and 90) are percentile of droplets with smaller than the defined diameter.

\subsubsection{Nanogel.}

The low viscosity of nanoemulsions has challenged their topical application. Thus, by adding a thickening agent, carbomer $940(2 \% \mathrm{w} / \mathrm{v})$, the nanoemulsion was transformed into a nanogel. Carbomer was first hydrated in the nanoemulsion $(120 \mathrm{rpm}$, overnight, ambient temperature). The sample's $\mathrm{pH}$ was then adjusted from 4 to 6.5-7 using an aqueous solution of $\mathrm{NaOH}(25 \% \mathrm{w} / \mathrm{v})$ for completing the gelling process. After that, the viscosity of nanogel was investigated using a rheometer machine at $25{ }^{\circ} \mathrm{C}$ (Anton Paar rheometer Company, model MCR-302, Austria). Besides, a blank gel was also prepared using the same manner; only CSEO was not used. 


\subsubsection{Impregnated nanogel on the surface of the NFs.}

Circular pieces of the Chi-PCL NFs with a diameter of $10 \mathrm{~mm}$ were punched. The nanogel $(9.15 \pm 0.1 \mathrm{mg})$ was then impregnated on each piece's surface, named NFsGel. Furthermore, the blank gel was also impregnated on other pieces and named NFsGel(-oil).

2.5. Evaluation of the leishmanicidal activity of CSEO, NFsGel, and NFsGel(-oil).

Serial dilution of CSEO in the concentration range of $5120-20 \mu \mathrm{g} / \mathrm{mL}$ was prepared using PBS's aqueous solution (containing $0.05 \% \mathrm{v} / \mathrm{v}$ DMSO) as a solvent. The leishmanicidal activity of the serial dilution and NFsGel, and NFsGel(-oil) was investigated using MTT assay. $400 \mu \mathrm{L} /$ well of the serial dilution or $400 \mu \mathrm{L} /$ well of the PBS solution containing pieces of NFsGel or NFsGel(-oil) was first added to 48 -well plates, separately. After that, $400 \mu \mathrm{L} /$ well of the suspension of each promastigote of L. major and L. tropica at the logarithmic phase was added. Promastigotes were cultured in the RPMI complete medium (10\% Fetal Bovine Serum and $1 \%$ penicillin-streptomycin); their number was set $250,000 /$ well.

After incubating the treated plates $\left(24 \mathrm{~h}\right.$ at $\left.25^{\circ} \mathrm{C}\right), 50 \mu \mathrm{L}$ of MTT solution $(0.5 \mathrm{mg} / \mathrm{mL})$ was added to each well and incubated for another $4 \mathrm{~h}$. Finally, $200 \mu \mathrm{L} /$ well of DMSO was added, and absorbance (A) of wells was read at $570 \mathrm{~nm}$. The viability at each well was calculated by equation 1 . This test was performed in triplicates; three control and blank groups were considered in each replicate. Control groups were filled with $800 \mu \mathrm{L}$ PBS solution, and blank groups contained $400 \mu \mathrm{L}$ RPMI complete medium (without promastigotes) and $400 \mu \mathrm{L}$ PBS.

Viability $(\%)=(($ Mean A sample-Mean A blank $)($ Mean A control-Mean A blank $)) \times 100(1)$

\section{Results and Discussion}

\subsection{Ingredients of CSEO.}

Overall, 32 components were identified in the CSEO using GC-MS analysis. Five major ingredients with high amounts are limonene (71.264\%), trans-p-2,8-menthadien-1-ol (4.956\%), cis-limonene oxide (2.587\%), trans-limonene oxide, $(2.294 \%)$, and trans-carveol $(2.906 \%)$.

\subsection{The leishmanicidal activity of CSEO.}

The leishmanicidal activity of CSEO on promastigotes of L. tropica and L. major is demonstrated in Figure 1. Because both promastigotes' viability was $\sim 95 \%$ at the concentrations of $10-40 \mu \mathrm{g} / \mathrm{mL}$, these concentrations possess negligible effect. However, by increasing the concentration to $160 \mu \mathrm{g} / \mathrm{mL}$ or higher levels, the viabilities were reduced to $10 \%$. The only point that showed a moderate effect on the promastigotes was $80 \mu \mathrm{g} / \mathrm{mL}$; the viability of $L$. major and L. tropica were approximately $30 \%$ and $25 \%$, respectively. Therefore, this concentration was chosen to compare the leishmanicidal effect of CSEO and its nano formulated form.

Furthermore, IC50s (lower and upper confidence limits) of L. tropica and L. major were observed at $151(93-245) \mu \mathrm{g} / \mathrm{mL}$ and $108(71-164) \mu \mathrm{g} / \mathrm{mL}$, respectively (CalcuSyn free version, Biosoft, UK). The leishmanicidal effect of other EOs against these promastigotes has also been found in the literature. For instance, IC 50 s of EOs of Zataria multiflora and Cymbopogon citratus against L. tropica was reported at 89.30 and $52.00 \mu \mathrm{g} / \mathrm{mL}$, respectively 
[23, 24]. Besides, EOs of Cymbopogon citratus, Rosmarinus officinalis, and Satureja bakhtiarica with IC50s of $149.10,260.00$, and $150.00 \mu \mathrm{g} / \mathrm{mL}$, respectively, also showed potency against L. major [25-27].

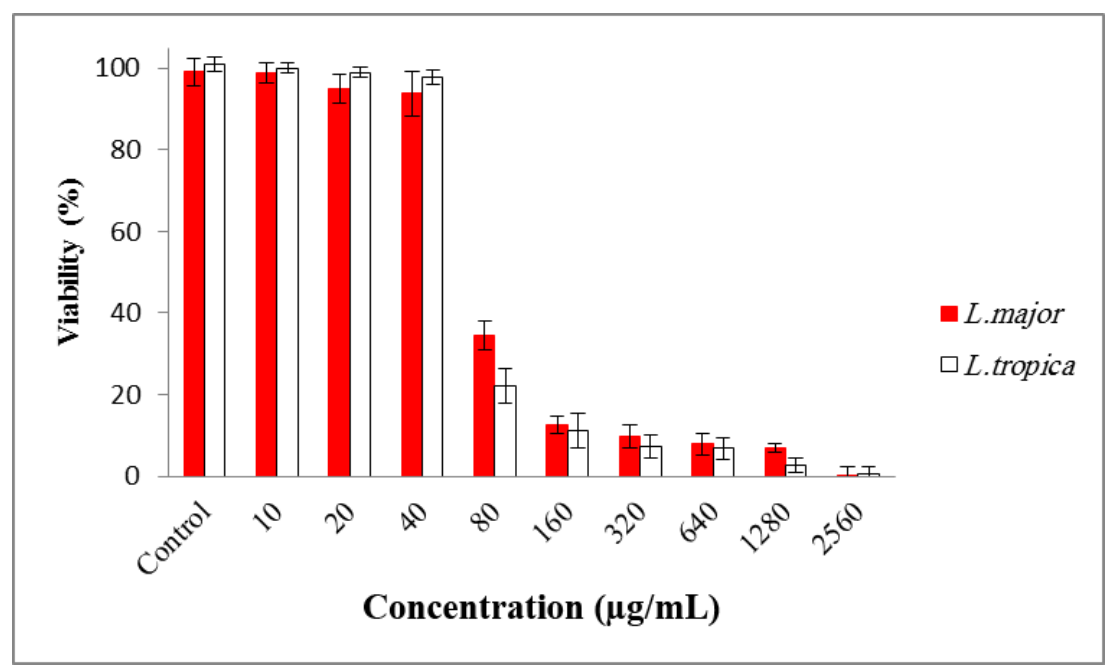

Figure 1. The leishmanicidal activity of CSEO.

\subsection{Prepared nanofibers and their characteristics.}

The SEM image of the prepared NFs with a $203 \pm 29 \mathrm{~nm}$ diameter is shown in Figure $2 \mathrm{~A}$. As the water contact angle with the NFs mat's surface was $109^{\circ} \pm 2$. It confirmed that the surface had a moderate hydrophobic property (Figure $2 \mathrm{~B} \& \mathrm{C}$ ).

Chi is a cationic, biocompatible, and biodegradable biopolymer obtained by chitin's deacetylation [28, 29]. It posses many biological activities, such as anti-fungi, -bacteria, and parasites [30-32]. Besides, PCL is a synthetic aliphatic polyester with hydrophobic properties. It is slowly degraded under physiological conditions $[14,15]$. Therefore, the preparation of Chi-PCL NFs leads to amphiphilic behavior in the final sample [33].

The results of this study were comparable with other studies. For example, by mixing different Chi $1 \%$ and PCL 10\% ratios, NFs with a range of $320-730 \mathrm{~nm}$ were reported [21]. In another study, by mixing Chi and PCL with a concentration of 1 and $8 \%$, respectively, NFs with a diameter of 100-200 $\mathrm{nm}$ were prepared [34]. Besides, the water contact angle with the surface of PCL-Chi NFs (6:20) was reported as $120^{\circ}$ [35]. In another study, the contact angle of PCL-Chi-gelatin NFs was $128^{\circ}$ [36]. The mentioned contact angle values are comparable with the result of this study; a slight difference is related to the ratio of PCL and Chi or using another extra polymer.

ATR-FTIR spectra of each polymer and the Chi-PCL NFs are depicted in Figure 3. In Chi spectra, a strong band in the region $3352-3290 \mathrm{~cm}^{-1}$ is belonged to $\mathrm{N}-\mathrm{H}$ and $\mathrm{O}-\mathrm{H}$ stretching. The absorption at around $2867 \mathrm{~cm}^{-1}$ is related to $\mathrm{C}-\mathrm{H}$ stretching; this band is characteristic of polysaccharides. $\mathrm{N}$-acetyl groups' residual appeared at $1644 \mathrm{~cm}^{-1}(\mathrm{C}=\mathrm{O}$ stretching of amide) and $1316 \mathrm{~cm}^{-1}$ (C-N stretching of amide). An absorption band at $1588 \mathrm{~cm}^{-1}$ was related to the $\mathrm{N}-\mathrm{H}$ bending of the primary amine. The absorption bands at $1374 \mathrm{~cm}^{-1}$ are associated with the $\mathrm{CH}_{3}$ bending vibration of Chi.

For the characterization of PCL powder, some band is standard. A broad and strong band in the region $3303 \mathrm{~cm}^{-1}$ is related to $\mathrm{OH}$. The absorption bands at 2942 and $2865 \mathrm{~cm}^{-1}$ are attributed to the PCL hydrocarbon's C-H stretching vibration. An absorption band at about 1710 
$\mathrm{cm}^{-1}$ is related to carbonyl groups' stretching vibration $(\mathrm{C}=\mathrm{O}$ stretching of ester). Furthermore, the characteristic absorption band in $1237 \mathrm{~cm}^{-1}$ belongs to the stretching vibration of $(\mathrm{C}-\mathrm{O})$.

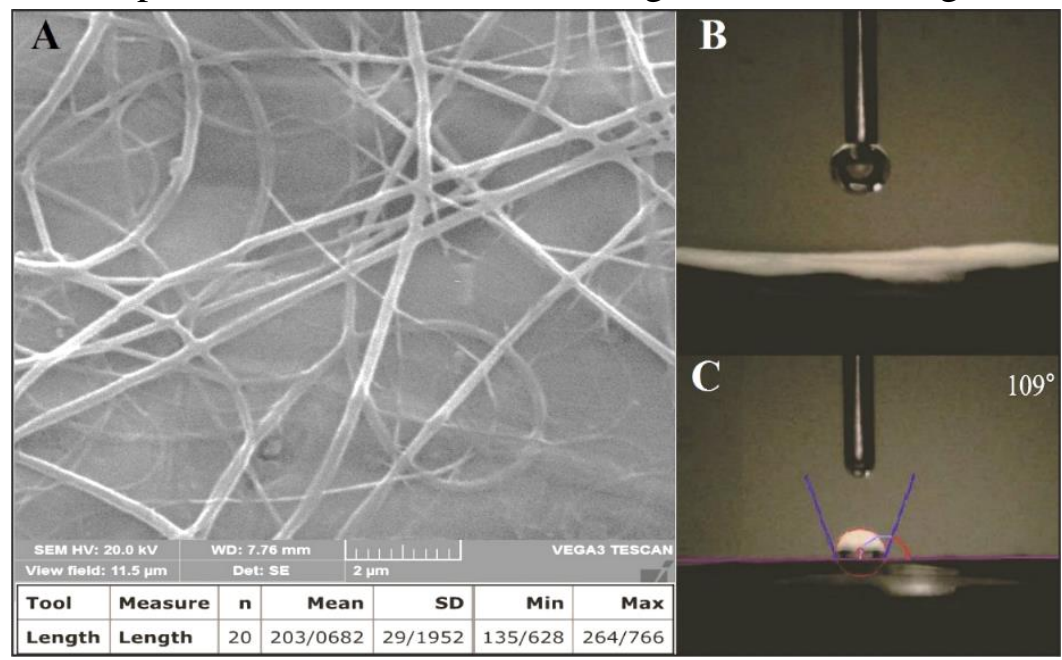

Figure 2. SEM image of prepared Chi-PCL NFs (A), Water droplet during injection (B) and after $5 \mathrm{~s}$ (C) for measurement of hydrophilicity of the NFs surface.

ATR-FTIR spectroscopy of Chi-PCL NFs has confirmed the presence of both PCL and Chi in achieved NFs. The broad peak at $3434 \mathrm{~cm}^{-1}$ belongs to the $\mathrm{O}-\mathrm{H}$ and $\mathrm{N}-\mathrm{H}$ groups of Chi. The specific peak at $2943 \mathrm{~cm}^{-1}$ showed that the $\mathrm{C}-\mathrm{H}$ stretching vibration of hydrocarbon in PCL and Chi. The strong peak at $1723 \mathrm{~cm}^{-1}$ proves the existence of $(\mathrm{C}=\mathrm{O})$ of PCL. Also, an absorption band at $1187 \mathrm{~cm}^{-1}$ confirmed the C-O stretching of the ester functional group of PCL.

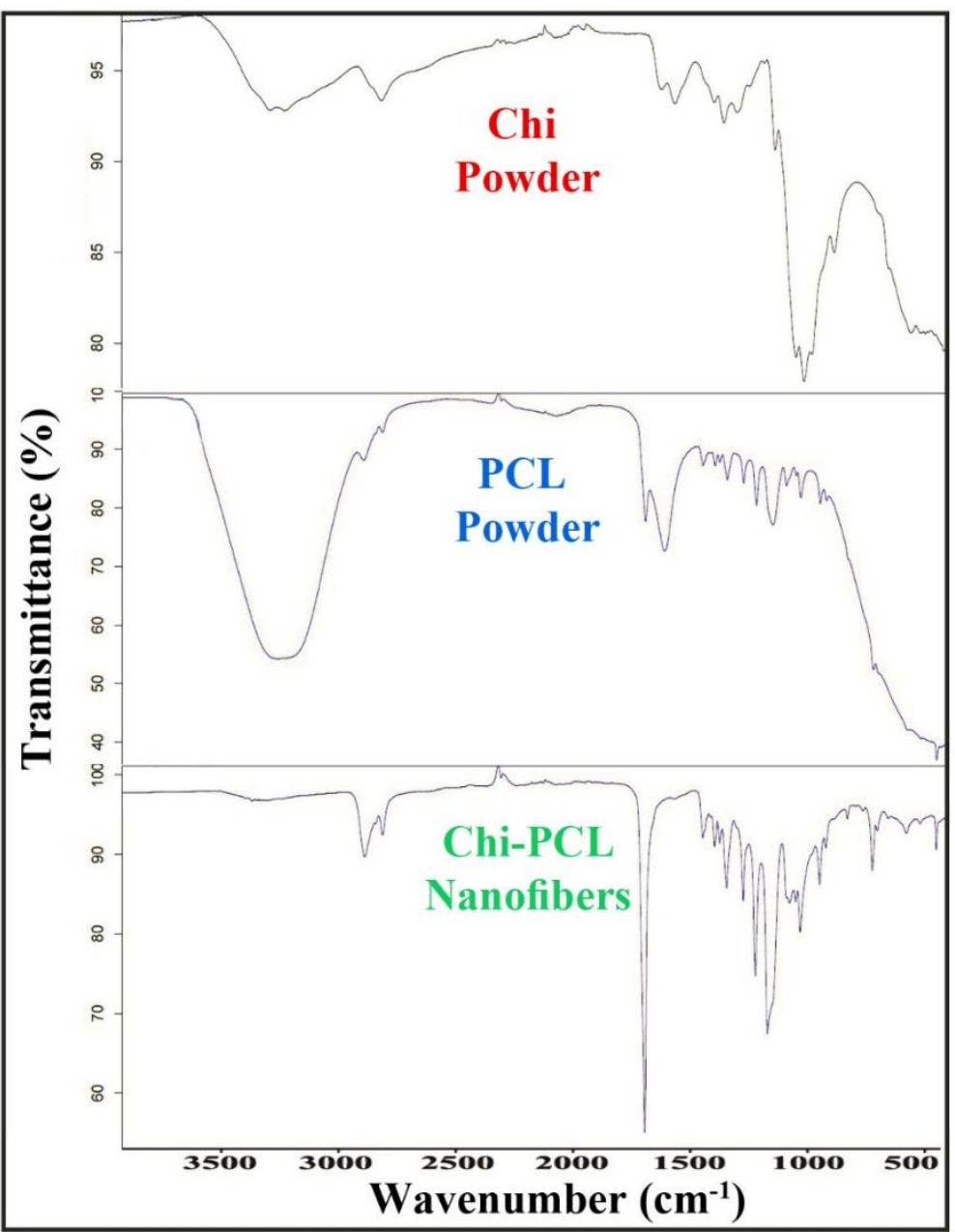

Figure 3. ATR-FTIR of Chi and PCL powders and electrospun NFs of PCL-Chi. 


\subsection{Prepared nanoemulsions-based nanogel and its characteristics.}

Figure 4A shows that the droplet size and SPAN of the prepared emulsion were $225 \pm$ $7 \mathrm{~nm}$ and $0.97 \pm 0.01$, respectively. Images of the nanoemulsion, nanogel, and blank gel and the effect of different shear rates on the viscosity of the nanogel are given in Figure 4B and C. A schematics of the impregnated nanogel on NFs (NFsGel and NFsGel(-oil)) is given in Figure 4D. The rheology of the nanogel follows non-Newtonian fluids; viscosity decreases by increasing the shear rate. The behavior of this nanogel is fitted with the Carreau-Yasuda model, a well-known equation for the viscosity of non-Newtonian fluids [37].

NGels have been widely used to improve the topical delivery of hydrophobic cargoes; e.g., a nanoemulsion-based nanogel of amphotericin B was prepared using carbomer 980 . The percutaneous permeation flux rate $\left(\mu \mathrm{g} / \mathrm{cm}^{2} / \mathrm{h}\right)$ of nanogel $(18.09 \pm 0.6)$ was better than nanoemulsion $(15.74 \pm 0.4)$ and drug solution $(4.59 \pm 0.01)[38,39]$.

Nowadays, it is accepted that nanoemulsions with small droplet sizes have better interaction with the microorganism's outer membrane. Besides, After the disruption of walls by surfactants, the cargo's effectiveness (e.,g EO) is enhanced [40-42]. Therefore, in the current research, CSEO was first formulated into nanoemulsion. Moreover, by converting nanoemulsions to nanogels, their viscosity increases, so they could have a better accumulation on the site, which leads to better hydration of the site [43]. The nanometric EO dispersion and the better hydration of the site lead to better penetration of the EO in to the locality [44].

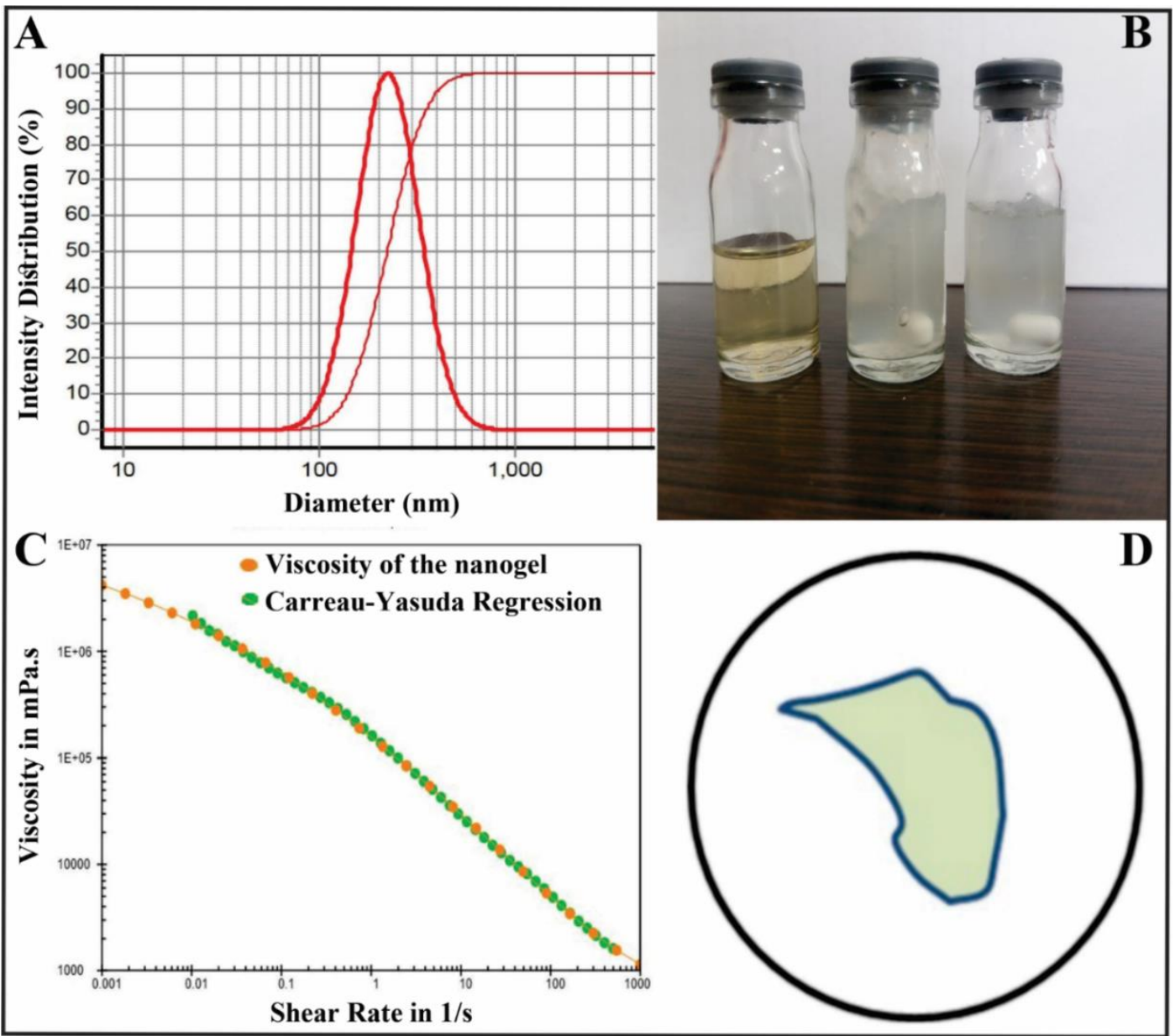

Figure 4. DLS analysis of the nanoemulsion (A), Images of the nanoemulsion, nanogel, and blank gel (B), Adaptation of viscosity of prepared nanogel to Carreau-Yasuda model (C), and schematic of impregnated nanofibers with nanogel (D). 
3.5. Leishmanicidal effect of nanofiber impregnated with nanogel (NFsGel).

The leishmanicidal activities of the CSEO $(80 \mu \mathrm{g} / \mathrm{mL})$, NFsGel(-oil), and NFs(Gel) are demonstrated in Figure 5. By applying the NFsGel in the MTT assay, the concentration of CSEO eventually reached $80 \mu \mathrm{g} / \mathrm{mL}$. Due to the leishmanicidal activity of Chi [45], NFsGel(oil) also had a significant effect on both of L. tropica and L. major in comparison to the control group (Independent sample t-test, sig < 0.05).

Besides, the leishmanicidal effect of NFsGel was significantly better than all samples (one-way ANOVA, sig < 0.05); the viabilities of $L$ major and L. tropica were reduced to less than $10 \%$. Interestingly, by impregnating $11 \mathrm{mg}$ of nanogel on the NFs (instead of $9.15 \mathrm{mg}$ ), the promastigotes' viabilities were reduced to $0 \%$.

Some studies have been reported on using NFs or nanoemulsions as anti-leishmania agents. However, no report was found on investigating the leishmanicidal effect of impregnated NFs with nanogel. From the literature, chitosan nanofilm's therapeutic effect on cutaneous leishmaniasis has been approved in the Balb/c model [46]. In another study, by formulating of EOs of Lavandula angustifolia ( $\mathrm{IC}_{50} 0.11 \mu \mathrm{L} / \mathrm{mL}$ ) and Rosmarinus officinalis (IC50 0.26 $\mu \mathrm{L} / \mathrm{mL}$ ) into nanoemulsion, their leishmanicidal effect was significantly improved against $L$. major $\left(\mathrm{IC}_{50}=0.08 \mu \mathrm{L} / \mathrm{mL}\right)$.

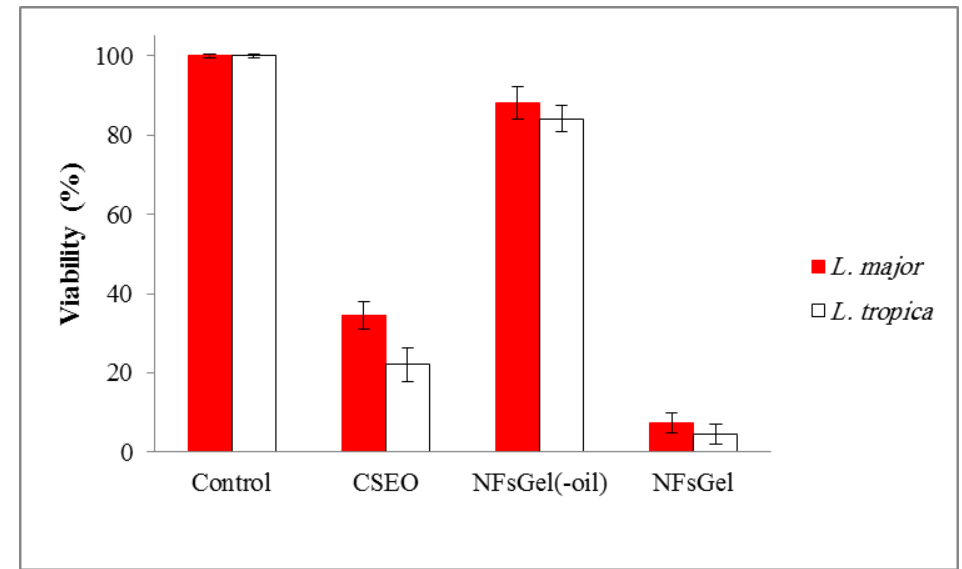

Figure 5. Leishmanicidal effect of CSEO, NFsGel(-oil), and NFsGel.

\section{Conclusions}

In this study, the leishmanicidal activity of CSEO was investigated. Its potency, stability, and easy usage in a topical manner were improved by preparing the nanoemulsionbased nanogel. Besides, by impregnating CSEO nanogel on the surface of Chi-PCL NFs (NFsGel), its efficiency was improved. The leishmanicidal effect of NFsGel was significantly better than the CSEO; it was reduced the viabilities of L. major and L. tropica to $0 \%$. NFs with nanometric meshes could also prevent the entry of environmental pathogens into the lesion and secondary infection. In this system, the amount of impregnated nanogel on the NFs mat could easily be adjusted as needed. Easy packaging and storage are other benefits of this system. The prepared prototype could be used as an excellent substance for in-vivo studies.

\section{Funding}

Fasa University of Medical Sciences has supported this study (Grant Number 97098). Furthermore, this research has also been ethically approved with the ID of IR.FUMS.REC.1397.094. 


\section{Acknowledgments}

This research has no acknowledgment.

\section{Conflicts of Interest}

The authors declare no conflict of interest.

\section{References}

1. Noorpisheh Ghadimi, S.; Sharifi, N.; Osanloo, M. The leishmanicidal activity of essential oils: A systematic review. 2020, 9, 300-308, https://doi.org/10.34172/jhp.2020.38.

2. Moemenbellah-Fard, M.D.; Abdollahi, A.; Ghanbariasad, A.; Osanloo, M. Antibacterial and leishmanicidal activities of Syzygium aromaticum essential oil versus its major ingredient, eugenol. Flavour and Fragrance Journal 2020, 35, 534-540, https://doi.org/10.1002/ffj.3595.

3. Laboudi, M.; Sahibi, H.; Elabandouni, M.; Nhammi, H.; Ait Hamou, S.; Sadak, A. A review of cutaneous leishmaniasis in Morocco: A vertical analysisto determine appropriate interventions for control and prevention. Acta Trop 2018, 187, 275-283, https://doi.org/10.1016/j.actatropica.2018.07.019.

4. Machado, M.; Santoro, G.; Sousa, M.C.; Salgueiro, L.; Cavaleiro, C. Activity of essential oils on the growth of Leishmania infantum promastigotes. Flavour and Fragrance Journal 2010, 25, 156-160, https://doi.org/10.1002/ffj.1987.

5. 1 Hajj, R.; Bou Youness, H.; Lachaud, L.; Bastien, P.; Masquefa, C.; Bonnet, P.-A.; El Hajj, H.; Khalifeh, I. EAPB0503: An Imiquimod analog with potent in vitro activity against cutaneous leishmaniasis caused by Leishmania major and Leishmania tropica. PLOS Neglected Tropical Diseases 2018, 12, https://doi.org/10.1371/journal.pntd.0006854.

6. Salah, I.; Abbasi, I.; Warburg, A.; Davidovitch, N.; Kotler, B. Ecology of Leishmaniasis in an urbanized landscape: Relationship of sand fly densities, and Leishmania tropica infection rates with reservoir host colonies. Acta Tropica 2020, 204, https://doi.org/10.1016/j.actatropica.2020.105332.

7. Echeverría, J.; Duarte Galhardo de Albuquerque, R.D. Nanoemulsions of Essential Oils: New Tool for Control of Vector-Borne Diseases and In Vitro Effects on Some Parasitic Agents. Medicines (Basel, Switzerland) 2019, 6, https://doi.org/10.3390/medicines6020042.

8. Ammar, A.H.; Zagrouba, F.; Romdhane, M. Optimization of operating conditions of Tunisian myrtle (Myrtus communis L.) essential oil extraction by a hydro-distillation process using a 24 complete factorial design. Flavour and Fragrance Journal 2010, 25, 503-507, https://doi.org/10.1002/ffj.2011.

9. Garcia, A.R.; Amaral, A.C.F.; Azevedo, M.M.B.; Corte-Real, S.; Lopes, R.C.; Alviano, C.S.; Pinheiro, A.S.; Vermelho, A.B.; Rodrigues, I.A. Cytotoxicity and anti-Leishmania amazonensis activity of Citrus sinensis leaf extracts. Pharm Biol 2017, 55, 1780-1786, https://doi.org/10.1080/13880209.2017.1325380.

10. Osanloo, M.; Assadpour, S.; Mehravaran, A.; Abastabar, M.; Akhtari, J. Niosome-loaded antifungal drugs as an effective nanocarrier system: A mini review. Curr Med Mycol 2018, 4, 31-36, https://doi.org/10.18502/cmm.4.4.384.

11. Bilenler, T.; Gokbulut, I.; Sislioglu, K.; Karabulut, I. Antioxidant and antimicrobial properties of thyme essential oil encapsulated in zein particles. Flavour and Fragrance Journal 2015, 30, 392-398, https://doi.org/10.1002/ffj.3254.

12. Rai, V.K.; Mishra, N.; Yadav, K.S.; Yadav, N.P. Nanoemulsion as pharmaceutical carrier for dermal and transdermal drug delivery: Formulation development, stability issues, basic considerations and applications. J Control Release 2018, 270, 203-225, https://doi.org/10.1016/j.jconrel.2017.11.049.

13. Ghaeini-Hesaroeiye, S.; Boddohi, S.; Vasheghani-Farahani, E. Dual responsive chondroitin sulfate based nanogel for antimicrobial peptide delivery. International Journal of Biological Macromolecules 2020, 143, 297-304, https://doi.org/10.1016/j.ijbiomac.2019.12.026.

14. Samadian, H.; Ehterami, A.; Sarrafzadeh, A.; Khastar, H.; Nikbakht, M.; Rezaei, A.; Chegini, L.; Salehi, M. Sophisticated polycaprolactone/gelatin nanofibrous nerve guided conduit containing platelet-rich plasma and citicoline for peripheral nerve regeneration: In vitro and in vivo study. International Journal of Biological Macromolecules 2020, 150, 380-388, https://doi.org/10.1016/j.ijbiomac.2020.02.102.

15. Abbasian, M.; Massoumi, B.; Mohammad-Rezaei, R.; Samadian, H.; Jaymand, M. Scaffolding polymeric biomaterials: Are naturally occurring biological macromolecules more appropriate for tissue engineering? International Journal of Biological Macromolecules 2019, 134, 673-694, https://doi.org/10.1016/j.ijbiomac.2019.04.197.

16. Jesus, S.; Soares, E.; Borchard, G.; Borges, O. Adjuvant Activity of Poly-e-caprolactone/Chitosan Nanoparticles Characterized by Mast Cell Activation and IFN- $\gamma$ and IL-17 Production. Molecular Pharmaceutics 2018, 15, 72-82, https://doi.org/10.1021/acs.molpharmaceut.7b00730. 
17. Unalan, I.; Endlein, S.J.; Slavik, B.; Buettner, A.; Goldmann, W.H.; Detsch, R.; Boccaccini, A.R. Evaluation of Electrospun Poly( $\varepsilon$-Caprolactone)/Gelatin Nanofiber Mats Containing Clove Essential Oil for Antibacterial Wound Dressing. Pharmaceutics 2019, 11, https://doi.org/10.3390/pharmaceutics11110570.

18. Ghafoor, B.; Aleem, A.; Najabat Ali, M.; Mir, M. Review of the fabrication techniques and applications of polymeric electrospun nanofibers for drug delivery systems. Journal of Drug Delivery Science and Technology 2018, 48, 82-87, https://doi.org/10.1016/j.jddst.2018.09.005.

19. Osanloo, M.; Arish, J.; Sereshti, H. Developed methods for the preparation of electrospun nanofibers containing plant-derived oil or essential oil: a systematic review. Polymer Bulletin 2020, 77, 6085-6104, https://doi.org/10.1007/s00289-019-03042-0.

20. Abdollahi, A.; Zarenezhad, E.; Osanloo, M.; Ghaznavi, G.; Pour, M. Promising antibacterial activity of a mat of polycaprolactone nanofibers impregnated with a green nanogel. Nanomedicine Research Journal 2020, 5, 192-201, https://doi.org/10.22034/nmrj.2020.02.010.

21. Yang, X.; Chen, X.; Wang, H. Acceleration of osteogenic differentiation of preosteoblastic cells by chitosan containing nanofibrous scaffolds. Biomacromolecules 2009, 10, 2772-2778, https://doi.org/10.1021/bm900623j.

22. Mohammadzadeh, L.; Rahbarghazi, R.; Salehi, R.; Mahkam, M. A novel egg-shell membrane based hybrid nanofibrous scaffold for cutaneous tissue engineering. Journal of biological engineering 2019, 13, https://doi.org/10.1186/s13036-019-0208-X.

23. Machado, M.; Pires, P.; Dinis, A.M.; Santos-Rosa, M.; Alves, V.; Salgueiro, L.; Cavaleiro, C.; Sousa, M.C. Monoterpenic aldehydes as potential anti-Leishmania agents: activity of Cymbopogon citratus and citral on L. infantum, L. tropica and L. major. Experimental parasitology 2012, 130, 223-231, https://doi.org/10.1016/j.exppara.2011.12.012.

24. Saedi Dezaki, E.; Mahmoudvand, H.; Sharififar, F.; Fallahi, S.; Monzote, L.; Ezatkhah, F. Chemical composition along with anti-leishmanial and cytotoxic activity of Zataria multiflora. Pharmaceutical Biology 2016, 54, 752-758, https://doi.org/10.3109/13880209.2015.1079223.

25. Sanchez-Suarez, J.; Riveros, I.; Delgado, G. Evaluation of the leishmanicidal and cytotoxic potential of essential oils derived from ten colombian plants. Iranian journal of parasitology 2013, 8, 129-136.

26. Shokri, A.; Saeedi, M.; Fakhar, M.; Morteza-Semnani, K.; Keighobadi, M.; Hosseini Teshnizi, S.; Kelidari, H.R.; Sadjadi, S. Antileishmanial Activity of Lavandula angustifolia and Rosmarinus Officinalis Essential Oils and Nano-emulsions on Leishmania major (MRHO/IR/75/ER). Iranian journal of parasitology 2017, $12,622-631$.

27. Mohammadpour, G.; Marzony, E.T.; Farahmand, M. Evaluation of the anti-Leishmania major activity of Satureja bakhtiarica essential oil in vitro. Nat Prod Commun 2012, 7, 133-136.

28. Kravanja, G.; Primožič, M.; Knez, Ž.; Leitgeb, M. Chitosan-based (Nano)materials for Novel Biomedical Applications. Molecules (Basel, Switzerland) 2019, 24, 1960, https://doi.org/10.3390/molecules24101960.

29. Moeini, A.; Pedram, P.; Makvandi, P.; Malinconico, M.; Gomez d'Ayala, G. Wound healing and antimicrobial effect of active secondary metabolites in chitosan-based wound dressings: A review. Carbohydrate Polymers 2020, 233, https://doi.org/10.1016/j.carbpol.2020.115839.

30. Qi, L.; Xu, Z.; Jiang, X.; Hu, C.; Zou, X. Preparation and antibacterial activity of chitosan nanoparticles. Carbohydrate Research 2004, 339, 2693-2700, https://doi.org/10.1016/j.carres.2004.09.007.

31. Zhang, M.; Tan, T.W. Insecticidal and fungicidal activities of chitosan and oligo-chitosan. Journal of Bioactive and Compatible Polymers 2003, 18, 391-400.

32. Kean, T.; Thanou, M. Biodegradation, biodistribution and toxicity of chitosan. Advanced Drug Delivery Reviews 2010, 62, 3-11, https://doi.org/10.1016/j.addr.2009.09.004.

33. Lin, X.; Yin, M.; Liu, Y.; Li, L.; Ren, X.; Sun, Y.; Huang, T.-S. Biodegradable polyhydroxybutyrate/poly$\varepsilon$-caprolactone fibrous membranes modified by silica composite hydrol for super hydrophobic and outstanding antibacterial application. Journal of Industrial and Engineering Chemistry 2018, 63, 303-311, https://doi.org/10.1016/j.jiec.2018.02.031.

34. Shalumon, K.T.; Anulekha, K.H.; Girish, C.M.; Prasanth, R.; Nair, S.V.; Jayakumar, R. Single step electrospinning of chitosan/poly(caprolactone) nanofibers using formic acid/acetone solvent mixture. Carbohydrate Polymers 2010, 80, 413-419, https://doi.org/10.1016/j.carbpol.2009.11.039.

35. Van der Schueren, L.; De Meyer, T.; Steyaert, I.; Ceylan, Ö.; Hemelsoet, K.; Van Speybroeck, V.; De Clerck, K. Polycaprolactone and polycaprolactone/chitosan nanofibres functionalised with the $\mathrm{pH}$-sensitive dye Nitrazine Yellow. $\quad$ Carbohydrate Polymers 2013, 91, 284-293, https://doi.org/10.1016/j.carbpol.2012.08.003.

36. Qian, Y.; Zhang, Z.; Zheng, L.; Song, R.; Zhao, Y. Fabrication and Characterization of Electrospun Polycaprolactone Blended with Chitosan-Gelatin Complex Nanofibrous Mats. Journal of Nanomaterials 2014, 2014, https://doi.org/10.1155/2014/964621.

37. Zare, Y.; Park, S.P.; Rhee, K.Y. Analysis of complex viscosity and shear thinning behavior in poly (lactic acid)/poly (ethylene oxide)/carbon nanotubes biosensor based on Carreau-Yasuda model. Results in Physics 2019, 13, https://doi.org/10.1016/j.rinp.2019.102245. 
38. Hussain, A.; Samad, A.; Singh, S.K.; Ahsan, M.N.; Haque, M.W.; Faruk, A.; Ahmed, F.J. Nanoemulsion gel-based topical delivery of an antifungal drug: in vitro activity and in vivo evaluation. Drug Deliv 2016, 23, 642-647, https://doi.org/10.3109/10717544.2014.933284.

39. Molina, M.; Asadian-Birjand, M.; Balach, J.; Bergueiro, J.; Miceli, E.; Calderón, M. Stimuli-responsive nanogel composites and their application in nanomedicine. Chemical Society Reviews 2015, 44, 6161-6186, https://doi.org/10.1039/C5CS00199D.

40. Lee, V.A.; Karthikeyan, R.; Rawls, H.R.; Amaechi, B.T. Anti-cariogenic effect of a cetylpyridinium chloride-containing nanoemulsion. Journal of Dentistry 2010, 38, 742-749, https://doi.org/10.1016/j.jdent.2010.06.001..

41. Ahmad, N.; Ahmad, F.J.; Bedi, S.; Sharma, S.; Umar, S.; Ansari, M.A. A novel Nanoformulation Development of Eugenol and their treatment in inflammation and periodontitis. Saudi Pharmaceutical Journal 2019, 27, 778-790, https://doi.org/10.1016/j.jsps.2019.04.014.

42. Najafi-Taher, R.; Ghaemi, B.; Amani, A. Delivery of adapalene using a novel topical gel based on tea tree oil nano-emulsion: Permeation, antibacterial and safety assessments. European journal of pharmaceutical sciences : official journal of the European Federation for Pharmaceutical Sciences 2018, 120, 142-151, https://doi.org/10.1016/j.ejps.2018.04.029.

43. Hathout, R.M.; Elshafeey, A.H. Development and characterization of colloidal soft nano-carriers for transdermal delivery and bioavailability enhancement of an angiotensin II receptor blocker. European Journal of Pharmaceutics and Biopharmaceutics 2012, 82, 230-240, https://doi.org/10.1016/j.ejpb.2012.07.002.

44. Lucca, L.G.; de Matos, S.P.; Kreutz, T.; Teixeira, H.F.; Veiga, V.F.; de Araújo, B.V.; Limberger, R.P.; Koester, L.S. Anti-inflammatory Effect from a Hydrogel Containing Nanoemulsified Copaiba oil (Copaifera multijuga Hayne). AAPS PharmSciTech 2018, 19, 522-530, https://doi.org/10.1208/s12249-017-0862-6.

45. Esboei, B.R.; Mohebali, M.; Mousavi, P.; Fakhar, M.; Akhoundi, B. Potent antileishmanial activity of chitosan against Iranian strain of Leishmania major (MRHO/IR/75/ER): In vitro and in vivo assay. Journal of vector borne diseases 2018, 55, 111-115, https://doi.org/10.4103/0972-9062.242557.

46. Bahrami, S.; Esmaeilzadeh, S.; Zarei, M.; Ahmadi, F. Potential application of nanochitosan film as a therapeutic agent against cutaneous leishmaniasis caused by L. major. Parasitology Research 2015, 114, 4617-4624, https://doi.org/10.1007/s00436-015-4707-5. 